\title{
Guidelines on the selection and transfer of materials from general collections to special collections
}

\section{Approved by the ACRL Board of Directors, July 2008}

by the ACRL Rare Books and Manuscripts Section Task Force to Review Guidelines on the Selection and Transfer of Materials from General Collections to Special Collections

\subsection{Introduction to the Guidelines}

Many libraries intentionally acquire rare books, serials, ephemera, documents, manuscripts, media (e.g., photographs, sound recordings, moving images), and other rare or unique items. However, virtually all libraries acquire materials that, with time and changing circumstances, become rare and gain special cultural and historical value. These materials may also gain signi cant monetary value in the marketplace. Librarians have a responsibility to identify the rare and valuable materials currently held in general and open stack collections and to arrange for their physical transfer to a library location that provides an appropriate level of access, preservation, and security. For many libraries the preferred transfer location is the special collections unit.

Some libraries provide environmentally sound and secure storage of rare materials in a location other than special collections, a location that provides an intermediate level of supervised access. While this transfer option is not addressed in these guidelines, it does require policy decisions similar to those considered here.

For de nitions and examples of terminology used in the guidelines, please refer to Section 5.2 Bibliography.

It is worth noting a transfer action related to, but not covered in, these guidelines: the transfer of materials out of a special collections unit. Once identi ed, these items may merit relocation to other protected areas of the library, transfer into the library s general stacks, or they may be deaccessioned and transferred to another institution. (See Appendix I. Transfers from Special Collections to Other Areas in the Library.)

\subsection{The Selection and Transfer Program}

Selection criteria and transfer policies vary from institution to institution and depend on the nature, strength, and use of the general and special collections; staf ng; and the physical setting. These guidelines are intended for general use by a range of library types and sizes, provide an overview of the considerations regarding selection criteria, and recommend procedures for an effective transfer policy to a special collections unit.

A successful selection and transfer program relies upon cooperation and coordination at every level of the library organization. In developing the program it is essential to obtain the support and approval of the library s senior administration. The written selection and transfer policy statement hereafter referred to as the transfer policy supports the library s mission and philosophical framework and documents the recommended procedures for everyone within the library. 
The transfer policy should be written by those who are administratively responsible for the program and should receive functional support from individuals and/or departments within the library responsible for: special collections, collection development, preservation, cataloging, reference, circulation, government documents, gifts, and systems.

\subsection{The transfer policy must:}

1. promulgate to the public the librarys de nition of and policy toward rare and special collections, ${ }^{1}$ justify the measures required to protect rare materials, and describe how implementing these measures will enhance the institution s ability to carry out its mission;

2. establish $\mathrm{rm}$ lines of authority to facilitate an effective and expeditious program;

3. list and document the criteria for the selection of items for transfer, which may be in uenced by the nature and strengths of the library s general and special collections;

4. set forth clear procedures to implement the transfer process. These should include: selection and approval of transfers, inspection by preservation staff, physical handling and processing, updating bibliographic and circulation records, and maintenance of security throughout the process.

The library may nd it helpful to contact professional consultants and colleagues from other libraries to help write the transfer policy, to re ne selection criteria, and to inventory the collections. Once completed, the transfer policy should be approved by the library s senior administration and incorporated into the librarys overall collection development policy.

\subsection{Transfer Policy Procedures}

The transfer policy has ve procedural phases:

1. identi cation of materials that $t$ the selection criteria;

2. review and decision to transfer;

3. preservation assessment;

4. cataloging review and processing, including location changes;

5. physical transfer to protected collections, e.g., special collections.

\subsection{Identification of Materials That Fit the Selection Criteria}

Ideally, a library will systematically inventory large segments of its general collections according to the selection criteria. Few librar-

\section{About the guidelines}

Materials located in a library's general collections may gain, over time, special cultural, historical, or monetary value. Librarians have a responsibility to identify and transfer these materials to a special collections unit to ensure that they remain accessible and that they receive an appropriate level of preservation and security. These guidelines provide an overview of the considerations regarding selection criteria and recommend procedures for an effective transfer policy.

The first edition (1987) of the Guidelines on the Selection of General Materials for Transfer to Special Collections was prepared by an ad hoc committee of the ACRL Rare Books and Manuscripts Section (RBMS), chaired by Samuel A. Streit and published in CERL News 48:8 (September 1987).

The second edition was approved by the ACRL Standards Committee in 1994 and revised in 1999.ACRL's RBMS Task Force to Review Guidelines on the Selection and Transfer of Materials from General Collections to Special Collections (2005-2008): Emily Epstein, Janet Gertz, Ron Lieberman, Daryl Morrison, Phyllis Payne, Andrea Rolich, Bruce Tabb, Jennifer Hain Teper, Charlotte B. Brown (chair). 
ies, however, nd such a comprehensive assessment possible. More often they choose instead to review materials and records selectively and incorporate identi cation into an existing library program or function. Other effective approaches include a selective review based on the history of the collection or a review that focuses on the areas of known strength. Many institutions nd it worthwhile to solicit suggestions and comments from faculty, students, researchers, professional appraisers, and other experts to aid in the identi cation of signi cant materials. The library may also publicize its willingness to consider recommendations from patrons. Regardless of the scope of the identi cation program, the direct inspection of both individual transfer candidates and their corresponding bibliographic records is essential.

\subsubsection{The identification process may include any of the following:}

a. reading the shelves (or the shelf list) in classi cations likely to contain candidates for transfer;

b. examining chronological les for early imprints of particular interest and value;

c. producing review lists from the online catalog based on name, title, imprint date, classi cation, place of publication, literary genre, subject, provenance, or other relevant elements;

d. consulting bibliographies, databases, dealer catalogs, dealer Web sites, and other reference tools.

\subsubsection{Transfer candidates may also be identified during routine handling associated with the following library functions:}
a. acquisitions;
b. binding;
c. cataloging;
d. circulation and stack maintenance;
e. collection surveys and assessments;
f. reformatting operations (digitization, photoduplication, microreproduction);
g. gifts and exchanges;

h. identi cation of materials for off-site storage;

i. interlibrary loan (Note: the scarcity of an item is sometimes revealed when conducting interlibrary searches);

j. inventory and shelf reading;

$\mathrm{k}$. preparation of exhibitions;

1. preservation;

m. reference;

n. retrospective conversion and/or enhancement of existing cataloging records;

o. weeding.

Transfer candidates may also be brought to the attention of library staff by patrons.

Titles identi ed as candidates for transfer and not yet removed from the circulating stacks can be flagged with a temporary marker, electronically agged in the online catalog record, or some other method of temporary identi cation can be used to prevent circulation prior to review. If bar codes and other permanent identi ers are not already af xed to transfer candidates, new bar codes/ identi ers should not be applied, pending the review and decision to transfer.

\subsection{Review and Decision to Transfer}

Not every item identi ed as a possible candidate will be chosen for transfer to special collections. For example, multiple copies of a title should be reviewed carefully to determine whether transfer of one or more copies is appropriate. Or, an item may be in such poor physical condition that it cannot be stabilized using standard conservation treatment, and thus loses its value as a candidate for transfer. In all cases, special collections staff (or staff assigned to this work) - in consultation with bibliographers, subject specialists, preservation staff, or faculty - should decide whether a given item merits transfer or should remain in the general collection.

\subsection{Preservation Assessment}

Physical changes made to an item after its original publication will diminish its value as a candidate for transfer. For this reason, a preservation assessment focusing on the physical condition of candidate materials 
should be conducted in consultation with special collections staff. The preservation assessment may occur either prior to the decision to transfer or after, depending on the item, the nature of the item s physical condition, and its anticipated use. For example, candidate items that are damaged or mutilated will require a preservation assessment prior to the transfer decision; the assessment will determine whether or not the damage can be remedied in order to make the item suitable for transfer. Alternatively, the preservation assessment may occur following the decision to transfer if the item has such value that it would be accepted into special collections despite its physical condition.

The preservation assessment will also include a recommendation as to when conservation treatment should occur, either before or after transfer. Treatment decisions should be made in conjunction with special collections staff and will range from minor repairs, stabilization, and protective housing to full conservation of the item.

\subsection{Cataloging Review and Processing}

Library users must be informed promptly when the location of an item has changed. One way to inform users is to update the catalog records to provide change of location information and adequate description. In some instances complete recataloging will be required. (See Appendix II. Changing Catalog Records.)

\subsection{Physical Transfer to Protected Collections}

Once the decision is made to transfer an item to special collections or another protected collection within the library, it is essential that the physical transfer be completed in a timely manner and that an appropriate level of security be provided during each phase of the transfer procedure.

\subsection{Transfer Criteria}

The criteria for what is rare or unique are not always obvious; reasons for considering items as valuable candidates for inclusion in a special collection will vary among institutions. The transfer decision should include an evaluation of the special qualities of an item relative to the institution s collection development policies. Selection for transfer implies that all similar items in the collection (e.g., all books in original bindings printed before 1845) ought to be considered. The constraints of implementing an effective transfer policy are familiar: the institutional mission and the resources needed to carry out that mission (personnel, space, equipment, technology, and budget). The dynamic balance between mission and resources will require a realistic approach and, most likely, compromise.

Still, in most cases a combination of general criteria will apply when evaluating an item for transfer: 1 . market value; 2 . age; 3 . physical and intrinsic characteristics; 4 . condition; 5. bibliographic and research value.

It is worth noting that the application of these criteria may vary from one institution to another. The following discussion of criteria is provided for general guidance and is not meant to prescribe what ought to be transferred. (See Appendix III. Sample Transfer Criteria.)

\subsection{Market Value}

Information on the market value and location of books and other materials in the general collections of libraries is readily available on the Internet. Therefore, library materials that have high monetary value are easily identied and especially vulnerable to theft. The transfer criteria will often include a threshold monetary value: the amount that the library de nes as a high value for an item. Items located in the librarys general collections with a market value at or above that threshold should be identi ed and considered for transfer. ${ }^{2}$ Additionally, the library s threshold value should be reviewed periodically for example, every ve years and adjusted as needed.

\subsection{Age}

The longer an item survives, the more it becomes one of a decreasing number of 
witnesses to its own time and place, and to the technology of its creation. Examples range from books printed during the hand press era, approximately 1455 to 1855 , to re insurance maps published from 1867 to 1970 . Therefore, age can be particularly useful as an initial criterion in identifying candidates for transfer.

Some libraries select a trigger date (threshold date) when reviewing materials for transfer, e.g. all items published before 1850 will be reviewed. Given that materials dating from 1900 are now over a century old, it is recommended that libraries relying on pre-set review dates revisit these parameters. It is possible that compelling reasons now exist to adjust the review dates.

An item $s$ age alone is a relative factor in the decision to transfer. There are often other factors related to age which help determine value, such as regional printing history. For example, books and other printed material from a speci c geographical location have signi cant value if published within the rst years or decades after printing was established in that locality; these published materials are known as regional incunables. The publication dates that de ne regional incunables will vary, for example: Pennsylvania (1685 1695), Texas (1817 1823), Alabama (1815 1825), and Oregon (1846-1856). ${ }^{3}$

In addition, the importance of the age of an object is relative to the development of the discipline it documents. For example, special collections that focus on modern science or medicine collect 20th-century journals containing seminal research articles in those elds.

With regard to technology, mid-19thcentury publications may be valuable and scarce if they contain illustrations incorporating early photographic processes. Representatives of new media or technology may also qualify items for transfer. For example, recording media, which went through their formative stages in the early 20th century, and early computer games are now being preserved at some institutions.

\subsection{Physical and Intrinsic Characteristics}

Library materials often have physical and intrinsic characteristics that qualify them as candidates for transfer. Some of these features may make them vulnerable to mutilation or theft and, therefore, require that they receive special protection. Library materials with qualifying characteristics for which there is wide, but not always unanimous, agreement include:

a. decorated end papers, unbound plates, vellum or publishers bindings, and book jackets (examples of physical characteristics related to the publication process);

b. library materials with signi cant provenance or evidence of association;

c. ne press editions;

d. valuable maps, original art, original photographs, ${ }^{4}$ or plates especially plates with hand-applied or lithographed color either as issued or as part of extra-illustrated volumes;

e. broadsides, posters, and printed ephemera (examples of library materials in special formats);

f. materials having local interest, about local history, or by local authors;

g. in-depth, subject-speci c collections;

h. books in unusual formats, erotica, or materials that are dif cult to replace (examples of library materials requiring security);

i. books with moveable parts, pop-up books, books having nonstandard sizes or shapes (examples of library materials with artistic and/or unique structural characteristics);

j. items for which ve or fewer copies are reported in the national online bibliographic database (OCLC WorldCat) or items for which only one copy is held in the geographic region (examples of library materials that are scarce or rare);

k. limited editions and small press runs;

1. custom-produced books and handmade books;

$\mathrm{m}$. books and other objects made out of unusual materials;

n. scrapbooks or photograph albums;

o. handwritten or typed materials. 


\subsection{Condition}

When reviewing library materials for possible transfer, condition may be the most important criterion, since all other values market, age, physical/intrinsic, bibliographic/researchmay be greatly affected by condition. Library materials that are badly worn, much repaired, or rebound should not automatically be transferred unless they represent a particularly scarce type of resource or present a compelling example(s) of the transfer criteria. For instance, it is now increasingly dif cult for researchers to locate examples of many 19th- and 20th-century printing and binding processes in ne original condition. So many volumes have been rebound that the richness of the decorative art applied to the original bindings and printed endpapers is increasingly dif cult to nd and study. Therefore, the reviewer must consider whether to transfer copies in less than perfect condition.

If the dust jacket is still present on a general collection copy, it should be retained when transferred. A book s dust jacket frequently contains important information including text, illustrative design, price, series, alternative titles, and biographical information about the author.

\subsection{Bibliographic and Research Value}

Bibliographic and research values should not be overlooked. For example, careful consideration should be given to reference works and periodicals still needed for general use since they frequently become quite valuable. Reference works and periodicals may be candidates for transfer especially if facsimile or other reprint editions are available to replace them on the open shelves. If the institution $s$ special collections have in-depth holdings on the history of native Americans in the Midwest, for example, reference titles about native Americans published in the late 19th to mid-20th-century might be considered for transfer.

Federal, state, and local government documents are also receiving attention as their research (and market) value increase.
Examples of particularly relevant government documents include: reports of 19th-century scienti $\mathrm{c}$ discoveries and expeditions, government publications containing maps or plates, ethnographic reports, and documents produced during major historical events (e.g., federal regulations for World War II internment camps).

Additional factors that may affect bibliographic and research value include:

a. market value among collectors and the antiquarian book trade;

b. evidence of censorship or repression;

c. seminal nature of or importance to a particular eld of study or genre of literature;

d. production for use by a private group with no subsequent public distribution.

\subsection{Selected Readings}

The process of developing, re ning, and updating a selection and transfer policy is ongoing and complex. It requires vision and good judgment, and pro ts from wide and informed reading. Although there is no literature dealing with transfer per se, the following Web sites and print publications may assist those charged with forming their librarys policies. Several of the sources can be used to determine market value and scarcity. ${ }^{5}$ In addition to the sources listed below, there are many print and Web-based bibliographies that include reference materials for speci $c$ disciplines and topics.

\subsection{Web Resources}

1. ACRL, January 2006, Guidelines for the Security of Rare Books, Manuscripts, and Other Special Collections, www.ala. org/ala/acrl/acrlstandards/securityrarebooks. htm (accessed 16 February 2008).

2. A C R L, J a nuary 2003 , Guidelines Regarding Thefts in Libraries, www.ala.org/ala/acrl/acrlstandards /guidelinesregardingthefts.htm (accessed 16 February 2008).

3. Council on Library and Information Resources (CLIR), November 2001, The Evidence in Hand: Report of the Task Force on the Artifact in Library Collections, www. 
clir.org/PUBS/reports/pub103/contents.html (accessed 16 February 2008).

4. Rare Books and Manuscripts Section, Bibliographic Standards Committee, January 2008, Directory of Web Resources for the Rare Materials Cataloger, hlib.nmsu.edu/rarecat/ (accessed 16 February 2008).

5. Rare Books and Manuscripts Section. Publications Committee, February 2006 (Revision 2005.2), Your Old Books, www. rbms.info/yob.shtml (accessed 16 February 2008).

\subsection{Bibliography}

1. Antiquarian Books, edited by Phillipa Bernard (Philadelphia: University of Pennsylvania Press, 1994).

2. Book Collecting: A Modern Guide, edited by Jean Peters (New York: R.R. Bowker, 1977).

3. G. L. Brook, Books and Book Collecting (London: Andre Deutsch, 1980).

4. John Carter, $A B C$ for Book Collectors, Eighth edition, revised by Nicolas Barker (New Castle, DE: Oak Knoll Press, 2004).

5. John Carter, Taste and Technique in Book Collecting; with an epilogue (London: Private Libraries Assoc., $1970[1977$ printing]).

6. Roderick Cave, Rare Book Librarianship, second edition revised (New York: R.R. Bowker, 1983).

7. Philip Gaskell, A New Introduction to Bibliography (New Castle, DE: Oak Knoll Press, 1995).

8. Geoffrey Ashall Glaister, Encyclopedia of the Book, second edition, introduction by Don Farren (New Castle, DE and London: Oak Knoll Press/British Library, 1996).

9. Jean Peters, Collectible Books: Some New Paths (New York: R.R. Bowker, 1979).

10. Lawrence Clark Powell, Rare Book Code, College \& Research Libraries 10 (October, 1949): 308.

11. Standard Citation Forms for Published Bibliographies and Catalogs Used in Rare Book Cataloging, prepared by Peter VanWingen and Belinda D. Urquiza, second edition (Washington, D.C.: Library of Congress, 1996).

12. Samuel Streit, Transfer of Materials from General Stacks to Special Collections, Collection Management 7 (Summer 1985): 3346.

13. Jim Walsh, Barbara Hulyk, George Barnum, Rare and Valuable Government Documents: A Resource Packet on Identi cation, Preservation, and Security Issues for Government Documents Collections (Chicago: Rare Books and Manuscripts Section [and] Government Documents Round Table [and] Map and Geography Round Table Joint Committee on Government Documents as Rare Books, American Library Association, 1993).

\section{Appendix I. Transfers from Special Collections to Other Areas in the Library}

Items that are not rare or do not require a high level of preservation or security are sometimes located in a library s special collections unit and may merit transfer into other protected areas of the library or into the general library stacks. Examples are: 1) subject collections (e.g., books about the Napoleonic era); 2) donations containing a mixture of rare and non-rare materials; and 3) items that become out-of-scope after changes are made to the collecting emphasis of special collections. While not ideal, the decision to transfer materials out of special collections may also be in uenced by space constraints.

It is recommended that the administrator in charge of special collections, in consultation with the collection development and preservation staff, give nal approval for materials that are deaccessioned from the special collections unit. Donor records, including existing deeds of gift, should be consulted to determine if there is an obligation for the item to remain in special collections. The impact that the transfer might have on the physical condition of the item once it is relocated to the circulating collections, such as loss of the dust jacket, added markings and stamps, damage during circulation, possible theft, should also be considered. 


\section{Appendix II. Changing Catalog Records}

Develop a local procedure that includes: searching the local catalog; examining existing records; updating or replacing bibliographic, item, and holdings records; creating shelf dummies (as needed); and physically remarking materials with new location information. NOTE: record refers to catalog cards, electronic records, or both as applicable.

a. Create lists of records to be changed.

b. Edit catalog records according to local cataloging requirements or standards.

As appropriate, edit catalog records to meet rare book cataloging standards. Consider adding notes for provenance, printers, binding, and citations.

These steps are recommended components for a transfer program. Libraries should strive to incorporate as many of them as feasible given local or outsourcing resources and expertise.

In addition to changing their bibliographic records, some libraries may choose to make a general announcement to their users that they have transferred a broad category of materials to a special collections area. For example, all books published before 1850 .

\section{Appendix III. Sample Transfer Criteria}

The following is an example of transfer criteria that might be employed by a public research university library established in the mid-19th century and located in the Midwest United States:

books published in [name of state] prior to 1835 ;

books published in the United States prior to 1850 ;

materials published prior to 1825 ;

children s books published prior to 1920 ;

travel books published prior to 1900; items published in the Confederate States of America (CSA), 1860 1865;

items published in Africa prior to 1851 items published in Latin American prior to 1851

items having market value over \$500.00;

items printed in editions of 100 copies or fewer;

publications by authors formerly residing in [name of city].

If special collections does not accept the item for transfer, forward the item to the subject specialist for review.

\section{Notes}

1. In most cases, a general de nition of and policy for rare and special collections are publicized. The selection criteria utilized by the library to identify potential rare and special materials are not publicly announced.

2. The urgency of determining market value for selected library items has increased since the guidelines were last published. Web sales of materials stolen from general library collections have occurred. Plates, maps, and other graphic materials are also subject to theft. For additional information on the security of special collection materials, see ACRL, January 2006, Guidelines for the Security of Rare Books, Manuscripts, and Other Special Collections, available online at www.ala.org /ala/acrl/acrlstandards/securityrarebooks. htm (accessed 16 February 2008). For a list of publicly reported thefts of rare books and other special collections materials, see Rare Books and Manuscripts Section. Security Committee. Security Resources, available online at www.rbms.info/committees/security/index.shtml (accessed 16 February 2008).

3. Roger J. Trienens, Pioneer Imprints From Fifty States (Washington, D.C.: Library of Congress, 1973).

4 . This includes library materials containing original photographs often pasted or glued into the item.

5. Web-based resources can provide general guidelines for determining scarcity and value. Library staff are advised to consult rare book, map, and/or manuscript specialists to con $\mathrm{rm}$ the assessments. $n$ 